\title{
PALAVRA E MÚSICA NA ESTÉTICA FINAL DE NIETZSCHE ${ }^{1}$
}

Henry Burnett (Unifesp) $)^{2}$

henry.burnett@unifesp.br

Resumo: Tomando como eixo fundamental $\mathrm{O}$ caso Wagner (1888), este artigo se desenvolverá a partir da relação entre palavra e música na estética musical tardia de Nietzsche. A utilização da ópera Carmen, de George Bizet, como possibilidade de antítese irônica ao programa da Obra de arte total, do compositor Richard Wagner, permite que se reflita sobre a estética-musical nietzschiana de um ponto de vista privilegiado. Por que Nietzsche teria se servido de uma obra que ele próprio considerou menor quando comparada ao drama musical de Wagner? A resposta a essa pergunta exige que se compreenda a fundo o valor nem sempre claro da palavra nas composições musicais retomadas por Nietzsche em diversos momentos de sua obra. Afinal, sua estética musical privilegiava a palavra significante ou a considerava mero aparato da música absoluta?

Palavras-chave: Friedrich Nietzsche; palavra; música.

Podemos dizer que o projeto estético-filosófico juvenil de Nietzsche não pode ser compreendido sem que fatores externos à filosofia ou mesmo à história da música estejam postos em primeiro plano. Tal procedimento já coloca os interessados em sua obra em estado de suspensão. Primeiro, uma obra filosófica que pretendia romper com a tradição secular da filosofia sem deixar de ser filosofia; e um projeto

\footnotetext{
${ }^{1}$ Recebido: 24-04-2015/Aprovado: 28-07-2015/Publicado on-line: 31-08-2015.

${ }^{2}$ Henry Burnett é professor da Departamento de Filosofia da Unifesp e bolsista de produtividade em pesquisa do CNPq, São Paulo, SP, Brasil.
} 
estético que se assentava sobre um momento arcaico, onde a música ainda não era arte, mas que, em sua nova configuração moderna, não poderia deixar de ser a música mais intensa. Uma dupla via que, ainda hoje, não pode ser compreendida em sua totalidade, mesmo passados mais de 100 de sua morte e do grande volume de pesquisas acumuladas em torno dela .

Mas a estética de Nietzsche nunca foi considerada canônica, como são canônicos os nomes de Aristóteles, Kant, Hegel ou mesmo tratados de estética posteriores a Nietzsche, como a Teoria estética, de Adorno, ao mesmo tempo em que seus pressupostos não deixaram de ser retomados positivamente por filólogos como Bruno Snell, filiado à escola de Ulrich von Willamowitz-Möllendorf que, como se sabe, foi o primeiro grande crítico do projeto nietzschiano; isso para ficarmos em apenas um exemplo, ainda que privilegiado. Snell comenta o legado estético e filológico de $\mathrm{Ni}$ etzsche nos seguintes termos: "Quando Nietzsche apresenta como uma característica do estilo decadente (O caso Wagner § 7) o fato de que as diversas partes se tornem independentes, não faz mais do que nos dar uma variante do juízo de Schlegel sobre Eurípedes e, como Schlegel, involuntariamente, caracteriza-se a si mesmo. Mesmo seu ódio contra Eurípedes é ódio contra uma parte de si. Seu olhar agudo destrói as ilusões, os sonhos, as esperanças que dão segurança ao homem, mas nele permanece uma nostalgia pelo que é simples, saudável e forte, pela arte verdadeira, que é para ele - como para Schlegel e Herder - criação sobre bases míticas. "Sem o mito, toda arte perde a saudável e originária força criativa”, diz Nietzsche no Nascimento da Tragédia, e esse mito está desagregado do espírito históricocrítico da nossa civilização. Amplia ele, assim, o juízo de 
Aristófanes sobre Eurípedes e o transforma, mais do que fez Schlegel, numa lei universal da civilização, revelando, com isso, que em sua inimizade por Eurípedes, esconde-se muita tristeza pelos males de seu tempo, muita nostalgia pela juventude da humanidade, muita hostilidade por tudo o que é histórico, qualquer que seja sua natureza" (SNELL 2009, p. 134).

Essa posição a um só tempo dentro e fora da história da estética exige dos estudiosos de hoje um empenho que vai além da exegese de textos. É necessário que o projeto estético de Nietzsche seja abordado a partir do momento histórico no qual ele foi gerado e, mais que isso, que se considere seriamente o material musical com o qual ele entrou em contato, e que lhe serviu como fonte tanto quanto o volume de leituras às quais ele se dedicou. Uma exigência que não parece despropositada - na medida em que tanto em obras juvenis como $\mathrm{O}$ nascimento da tragédia, ou em obras tardias como O caso Wagner, exemplos extraídos da produção musical de sua época foram mobilizados como fonte essencial para suas reflexões estéticas.

Assim Nietzsche retomou tragédias clássicas, coletâneas de canções folclóricas, óperas e, por fim, o drama musical wagneriano. O comentário de Bruno Snell não é apenas uma ilustração, antes deixa claro que a retomada por $\mathrm{Ni}$ etzsche de obras clássicas do período de Eurípedes significava uma preocupação não apenas com o rigor formal, filológico, mas, principalmente, com o momento histórico final, exatamente onde ele se encontrava, na ponta extrema da história da arte. Décadas antes da Teoria estética de Adorno, Nietzsche já indicava que as obras, os objetos da produção das artes, eram essenciais como "conteúdos de verdade", ainda que sua perspectiva fosse ainda muito dis- 
tinta da que Adorno viria a assumir.

Nietzsche inicia seu programa editorial, em 1871, retomando, como filólogo, os textos das tragédias gregas. Da mesma forma, num movimento de reinterpretação da modernidade a partir dessa chave clássica, ele se apossava do drama musical wagneriano, como espelho e prolongamento da imagem clássica tal como ele a interpretava. Nessa retomada estavam em jogo tanto o estatuto da Antiguidade quanto seu significado na ponta extrema da filosofia da arte. O objetivo deste artigo é circunscrito a uma questãochave da sua estética-musical: que papel a palavra exercia na música grega e qual o seu lugar na estética nietzschiana em sua dinâmica, ora afirmativa ora negativa, acerca do drama musical de Wagner e de compositores como Bizet? Podemos dizer que Nietzsche sustenta a união dos domínios do teatro, da poesia e da música na sua união clássica quando defende a primazia do drama musical de Wagner? Uma pergunta que não pode ser respondida apenas levando em consideração a perspectiva de uma obra como $\mathrm{O}$ nascimento da tragédia, a despeito de sua centralidade. Somente através de uma outra obra, da chamada fase da maturidade, $\mathrm{O}$ caso Wagner, podemos discutir o estatuto da palavra tomando distância da exacerbada posição juvenil que Nietzsche assumia em torno do que podemos chamar de um verdadeiro programa estético-musical, algo que precisava ser executado.

Por isso, ainda uma vez, o comentário de Bruno Snell precisa ser devidamente analisado. Ao destacar que Nietzsche estava preocupado com "os males de seu tempo", Snell não distingue as obras da primeira e da última fase. A passagem supracitada começa com uma referência a' $\mathrm{O}$ caso Wagner, de 1888, para depois recuar a'O nascimento da tragédia, de 1871. O movimento tem um mesmo propósito: o 
diagnóstico sobre a decadência exposto na obra de 1888 não se distingue dos males que a perda do mito causaram na configuração geral das artes e da humanidade tal como Nietzsche a entendia na obra inicial. Trata-se, como acertadamente aponta Snell, de um mesmo problema, tratado a partir de uma só chave: a arte. Mas ele diz mais quando cita o trecho do primeiro livro de Nietzsche: "Sem o mito, toda a arte perde a saudável e originária força criativa”. O mito é a chave que permite a Snell ligar as duas obras. É, de fato, a partir do mito que o problema da decadência é retomado na maturidade. $\mathrm{O}$ recurso à personagem Carmen, da ópera homônima de Bizet, operado em $\mathrm{O}$ caso Wagner, não passa de uma reinterpretação do mito trágico, de sua força criativa e de sua potência original, exatamente como Nietzsche o interpretava desde os primeiros movimentos de sua estética. Por isso é necessário enfrentar os objetos e as obras de arte como fonte principal para uma análise do estatuto da palavra na estética de Nietzsche.

A diferença entre os dois momentos é justamente o objeto. Na obra de 1871 Nietzsche afirma: "A força hercúlea da música: é ela que, chegando na tragédia à sua mais alta manifestação, sabe interpretar o mito com nova e mais profunda significação" (NIETZSCHE 1993, p. 71). Interpretar o mito através da música, é o que sugere o projeto inicial. Como Nietzsche executava esse difícil programa? Recuando como leitor - e como ouvinte hipotético - ao que ele julgava ser o cerne do mito trágico, o sumo conservado em textos como As Bacantes. Um procedimento desde sempre fadado à desconfiança, porque não passava da reativação de uma forma de sensibilidade há muito perdida. Nietzsche se julgava apto a reconstruir aquela estética grega, é preciso reiterar, como ouvinte e leitor. Para tanto, enfrentava as 
obras com grande afinco, lendo Aristófanes, Eurípedes, Arquíloco, Heráclito, Sófocles, Sócrates; então, num segundo momento, vai a Goethe, Shakespeare, Schlegel, Schopenhauer, Winckelmann, Lessing e, por fim, ouvindo Beethoven, Bach, Wagner, Palestrina e todas as óperas e montagens do período. Sem falar em todas as referências secundárias. Trabalho, sem dúvida, de um esteta seguro do valor das obras.

Nenhum autor ou obra citada foi retomado em nome de alguma erudição filológica - ainda que Nietzsche a possuísse de sobra - mas sempre com extremo rigor e com função clara. Nietzsche nunca separou a estética das obras de arte - um procedimento que somente com Adorno tomaria a forma atual, cujos preceitos determinam a importância de não separar precisão teórica da análise cerrada das obras de arte. Assim podemos reconstruir o percurso que, desde seus primeiros escritos, Nietzsche forjou para um entendimento da música de seu tempo .

Seria impossível negar que Nietzsche não tivesse plena consciência da situação social da música do seu tempo. Desde os seus primeiros escritos, podemos encontrar uma rígida preocupação com os efeitos da produção musical e com sua origem remota, como nesta anotação intitulada "Sobre a essência da música", do início de 1863, aos 19 anos: "Nem mesmo o compositor pode julgar o efeito que ele causa, ele próprio pode tornar-se completamente diferente da agitação que produz, ele não descreve, quando compõe, seu próprio estado de ânimo, ao menos não precisa disso, mas seu estado de ânimo estimula sua fantasia musical, e este pode ser o resultado de suas ideias" (NIETZSCHE 1994, p. 71).

A passagem mostra que desde os primeiros textos de 
Nietzsche sobre música o papel da subjetividade exerce uma importante função, mas que nem sempre essa função é clara. O estado de ânimo do compositor, que na visão de $\mathrm{Ni}$ etzsche se julga capaz de definir o efeito que sua música surtirá nos ouvintes, não é capaz, ao final, de resolver a forma final de recepção dessa música, isto é, seus efeitos sobre a audição absoluta. Podemos dizer que essa anotação de juventude contém o embrião da estética-musical de Nietzsche.

Tudo o que seria posteriormente enquadrado por sua obra pode ser analisado a partir da questão geral sobre a origem da obra de arte. Na primeira fase de sua obra, a palavra pertence à música - embora não se equipare a ela. É o que mostra o final d'O nascimento da tragédia e a defesa quase intransigente do papel do instinto apolíneo em sua configuração mais clássica, ou seja, como plástica perfeita. É o momento onde a obra de Nietzsche adere ao projeto estético de Richard Wagner sem nenhuma decisiva restrição. É o único momento de sua obra onde podemos falar em uma defesa do mito de forma desenfreada. Tratava-se, como se sabe, de uma justificação metafísica da arte dramáticomusical, e que não seria retomada com a mesma intensidade em nenhum outro texto.

Nietzsche seria capaz de afirmações graves naquele momento inicial, como quando afirma que "Somente para aquele que canta junto há uma lírica, há música popular: o ouvinte se coloca perante ela como perante uma música absoluta" (NIETZSCHE 2007, p. 181). Ele se referia ao significado da canção popular na origem da música, ao papel de um poeta como Arquíloco em relação ao valor histórico de Homero. Embora ciente do valor do drama musical wagneriano para a história da música, Nietzsche não deixa de for- 
necer importantes análises sobre a esfera popular da produção musical. $O$ vínculo entre o drama musical e a canção popular era justamente o uso da palavra. Em vários momentos, Nietzsche parece não distinguir o valor dessa palavra em domínios aparentemente avessos como Wagner e o folclore; o que explica a importância atribuída ao mito no período inicial de sua obra. A origem da música residia justamente num reencontro da sensação arcaica perdida; daí o significado valor do culto a Dioniso. A partir dessa valorização exacerbada da palavra, não podemos concluir que $\mathrm{Ni}$ etzsche ignorasse a grande tradição que tinha Beethoven como seu grande ápice, e nem a valorização da música absoluta com a qual Nietzsche se identificava enviezadamente falamos aqui do célebre ensaio Do belo musical, de Eduard Hanslick.

Justamente em função de tudo que resumimos até aqui, o uso que Nietzsche faz da ópera Carmen em seu último período de produção, principalmente n'O caso Wagner, permite leituras díspares. Alguns intérpretes chegam a defender a ideia de que Nietzsche desacreditava na força do mito naquele momento: "Nietzsche rompeu com a ideia de que a mitologia poderia regenerar um povo e que a arte poderia ser o substituto para a religião" (GOETZ 2001, p. 4). Mas essa interpretação, que vê na aproximação com Bizet apenas uma estratégia de manutenção da oposição a Wagner, num uso literalmente irônico da ópera, não é unânime. Paolo D'Iorio, em um longo artigo sobre as anotações feitas por Nietzsche na cópia da partitura de Carmen, e que hoje encontra-se no Goethe- und Schiller-Archiv, de Weimar, vai muito além dessa interpretação: "Todavia, quando se fala em coragem e fatalismo, a figura central da ópera é, evidentemente, Carmen, que havia tido coragem de viver e de mor- 
rer segundo a sua moral boêmia: livre diante de todos os homens, fatalista diante do destino. E o destino se anuncia numa célebre passagem, colocada na metade da ópera: a ária das cartas de baralho. 'Música fatalista de G. Bizet', ${ }^{3}$ é o comentário lapidar de Nietzsche. Ainda em 1888, no início do Caso Wagner, o adjetivo 'fatalista' retorna nas páginas dedicadas a Bizet: 'Esta música é má, refinada, fatalista', 'O amor como fatum, como fatalidade, cínico, inocente, cruel e por isso mesmo natureza'” (D'IORIO 2012, p. 222).

Ao contrário de uma interpretação que vê na escolha de Nietzsche uma opção retroativa ou mesmo regressiva, D'Iorio acredita num uso essencial e programático da ópera de Bizet. Segundo essa vertente, Nietzsche identificou-se profundamente com a tragicidade do libreto, com a impetuosidade da personagem e com os laços que ele firmava entre sua obra e a descoberta de Carmen. "Por que a música de Bizet atingira Nietzsche a ponto de causar-lhe uma admiração quase entusiasta? Porque, provavelmente, em 'Carmen', Nietzsche via a expressão de sua própria filosofia” (SICA 2002).

Isso significa que podemos até mesmo falar em traços de identificação entre Nietzsche e a personagem de Merimée? Talvez isso seja um excesso, mas não são poucos os autores que sustentam uma ligação profunda entre Nietzsche e o ambiente ao qual Carmen reporta ouvintes como ele. Ainda no estudo de Paulo D'Iorio, lemos: "Certo: ironia e verdade, se quisermos parafrasear Goethe, porque não resta dúvida que Nietzsche também era sensível ao fascínio romântico de Veneza; mas, sensível como pode ser um filósofo que superara intelectual e sentimentalmente estes es-

\footnotetext{
3 "Fatalistische Musik des G. Bizet", p. 265 [da fonte consultada], (N. do A.).
} 
tados de ânimo e os filosofemas românticos que conhecera sobretudo na juventude. E a frase irônica 'Alguém a teria escutado?' esconde a melancolia da solidão, a consciência que nem uma alma gêmea nem a essência metafísica do mundo responderiam ao canto de sua alma" (D'IORIO 2012, p. 213).

É a partir da compreensão de que Nietzsche esteve até seus últimos textos plenamente consciente do nível de exigência cobrado em relação ao drama musical wagneriano desde $\mathrm{O}$ nascimento da tragédia, que se pode falar em uma estética-musical tardia ao mesmo tempo devedora e independente em relação ao estatuto da palavra, tal como Nietzsche a compreendia na juventude. Compreender o uso e o significado da palavra nos dois extremos de sua obra permite analisar como ele permaneceu íntegro na sua crença musical mesmo quando tudo parecia distante e sua solidão imperava como imagem final. Esse deslocamento nem sempre pode ser percebido em sua singularidade.

Se ele "superara intelectual e sentimentalmente estes estados de ânimo e os filosofemas românticos que conhecera sobretudo na juventude", isso não significa, como mostra o comentador, que deixasse de existir um "canto de sua alma”, pleno de exigências. Mais adiante D'lorio afirma que "O filósofo cético e desencantado, que dissecou a natureza retirando dela a essência metafisica e historicizando os movimentos próprios do sentimento, ficou sozinho. Apenas com o consolo da ironia e a musa da poesia" (D'IORIO 2012, p. 213). Isto é muito distinto da ideia de um abandono das hipóteses juvenis, de uma ruptura radical entre suas ambições redentoras e a explicitação de sua concepção derradeira. Para entendermos isso, é fundamental que o lugar da palavra seja analisado em sua significância mais exa- 
ta. Aqui, categorias exteriores à filosofia precisam ser invocadas, como a forma musical e seu desenvolvimento no conjunto da história das ideias.

Quando Wagner escreve seu Beethoven com a intenção de homenagear, mas também de posicionar histórica e musicalmente seu antecessor, ele o faz indicando não as qualidades formais das composições sinfônicas de Beethoven, mas sua identificação com a nação alemã. Se Wagner poderia ter estabelecido princípios formais de análise da música instrumental de seu tempo, ele nos deixou outrossim subsídios acerca da interpenetração entre a forma musical e a política, esquadro complexo que tentei analisar em uma resenha ao livro. Para Nietzsche, a palavra significante não deveria ser um espelho da identidade nacional de seu país, nem tampouco a grande elaboração formal da música instrumental. $\mathrm{O}$ que interessava a Nietzsche era o vínculo entre a palavra e seus atributos linguísticos com o cerne da origem mítica do homem. Ou dito de outro modo: Nietzsche pretendia reencontrar na modernidade uma possibilidade de restaurar a força da palavra. D'Iorio demonstra isso de modo pouco convencional: "Se o mundo é um cosmos, um todo ordenado e regulado por um princípio único, o filósofo que quiser descrevê-lo e, por assim dizer, reproduzi-lo num livro, poderá e deverá utilizar da forma sistemática, por exemplo Espinoza, Hegel, Schopenhauer. Mas se o mundo é um caos, privado de lógica e regularidade, quase privado de um princípio unitário, e se o filósofo não tem a intenção de encontrar a palavra mágica que o defina em essência e devir, como poderíamos comunicar o pouco que restou para compreendê-lo? Nietzsche utiliza o aforismo" (D'IORIO 2012, p. 219).

De certo modo, mas não sem ponderações, podemos 
dizer que Nietzsche acreditou novamente na força da palavra mítica quando ouviu Carmen. É preciso reiterar essa necessária mediação porque seria impossível acreditar ou defender que Nietzsche pudesse estar alheio ao que se passava no terreno da composição, isto é, que Nietzsche ignorasse o significado da incursão wagneriana no ambientelimite do cromatismo, tal como ele se configurava naquele momento. Isso é muito importante, porque o uso que $\mathrm{Ni}$ etzsche faz de Carmen vai além, como mostram suas observações à margem da partitura, de uma audição deslumbrada, de uma assimilação romântica da ação dramática da personagem. Nietzsche estava interessado na força integral da obra, que não podia ser avaliada por sua posição "vanguardista", já que sua forma nada encerrava de avanço em relação ao que estava em curso no drama musical wagneriano. Podemos constatar isso já no início d'O caso Wagner: "Posso acrescentar que a orquestração de Bizet é quase a única que ainda suporto? Essa outra orquestração atualmente em voga, a wagneriana, brutal, artificial e "inocente" ao mesmo tempo, e que assim fala simultaneamente aos três sentidos da alma moderna - como me é prejudicial essa orquestração wagneriana!" (NIETZSCHE 1999, p. 11).

O trecho mostra que Nietzsche também compreendia a ópera de Bizet de um ponto de vista estrutural, isto é, a partir de sua forma musical. O ambiente no interior do qual Nietzsche elabora sua estética musical é dos mais significativos do ponto de vista da história da música. É justamente ali, no final do século XIX, que a música sofre sua mais radical operação de revigoramento, ainda que sob os escombros do esgotamento do mais longo sistema musical até hoje desenvolvido: o tonalismo. "O tonalismo enquanto sistema de organização da totalidade funcional das obras 
que havia orientado, de maneira hegemônica, a composição musical a partir do século XVIII chegara à sua exaustão" (SAFATLE 2006, p. 173). Por essa razão, e considerando o lugar retroativo que Carmen ocupa em relação à mais avançada das formas composicionais do período - o drama wagneriano -, se faz necessário analisar o recurso de Nietzsche à obra de Bizet nos movimentos finais de sua obra. $\mathrm{Pa}$ rece-nos óbvio que não se pode compreender seu recurso sem que compreendamos a "concessão" que faz a Bizet, ou dito de outro modo, que tenha escolhido uma ópera tradicional que formalmente não se equiparava ao oponente Wagner. Algo que o próprio Nietzsche não deixou de anotar: "O que digo sobre Bizet você não deve levar a sério; tal como sou, Bizet não entra em consideração para mim. Mas como antítese irônica a Wagner isto funciona bem; seria uma absoluta falta de gosto de eu partisse de um elogio de Beethoven, digamos". ${ }^{4}$

Do que Nietzsche estaria falando aqui? As comparações são extremamente importantes. Como reagir a Wagner e sua hegemonia? Por que não Beethoven, onde a forma sinfônica teria chegado no seu ponto mais alto e poderia fazer frente ao retrocesso wagneriano da composição atrelada à encenação e aos efeitos? Nietzsche tem consciência total da questão formal aqui, mas ainda assim invoca Bizet ("ironicamente”), para por termo a um problema que não se esgotava na racionalização das formas composicionais, mas que exigia outra postura, ainda mais radical de uma implosão formal do sistema tonal. Numa outra carta ao organista e diretor musical Carl Fuchs, Nietzsche posiciona claramente sua crítica formal a Wagner: "A expressão wagneriana 'me-

${ }^{4}$ F. Nietzsche, carta a Carl Fuchs, 27/12/1888, in “Apêndice” a'O caso Wagner, op. cit., p. 105. 
lodia infinita' manifesta, da maneira mais charmosa, o perigo, a ruína do instinto e da boa fé, da boa consciência. A ambiguidade rítmica, mediante a qual já não se sabe e nem se deve saber onde começa o rosto e termina o pescoço, consiste, sem dúvida alguma, num expediente artístico com o qual efeitos maravilhosos podem ser alcançados - o Tristão, por exemplo, é pródigo nisso -, mas, como sintoma de toda uma arte, ela é e continua a ser, apesar disso, o sinal de dissolução. A parte assenhora-se do todo, a frase da melodia, o instante do tempo (e também do tempo musical), o pathos do ethos... Mas, isso é décadence, um termo que, tal como nos parece ser evidente, não deve rechaçar, mas apenas descrever algo" (BARROS 2012, p. 139-140).

A falta de estrutura formal, o processo que refletiria mais o espírito de uma época que a fraqueza de um compositor, os sintomas da decadência são para Nietzsche indícios de que o andamento dos procedimentos composicionais não apontava para um revigoramento, mas para uma dissolução da música; ou talvez seja mais adequado dizer que sua preocupação se concentrava nos processos que regiam a dinâmica obra/público e de como a forma musical desenvolvida por Wagner influenciava negativamente essa relação. Ainda uma vez, sua crítica tem um foco preciso: tudo resulta em um "expediente artístico" cujo resultado são "efeitos maravilhosos", cuja função se justificava plenamente na relação entre público e obra, um novo tipo de dependência que, hoje se sabe, daria o tom dali por diante .

Se Nietzsche não poderia intuir os resultados dessa lógica de dependência - já que não podemos falar em mercado de música naquela época - sem dúvida foi um dos primeiros a condená-la veementemente já no embrião. Mesmo em obras de importantes críticos musicais atuais, 
encontramos esse legado de Nietzsche bem demarcado, como é o caso de Alex Ross. Ao mencionar Cocteau e seu desejo por uma música "para todos os dias", oposta aos resquícios wagnerianos que teimavam em subsistir mesmo depois da guerra, Ross retoma Nietzsche como argumento afirmativo, já que teria sido o filósofo o primeiro a diagnosticar esse sintoma quando criticara a "mentira do grande estilo" wagneriano. Nessa e nas demais referências, o crítico estadunidense se refere a Nietzsche como um visionário no terreno da crítica musical (ROSS 2009).

Se retornarmos à Carmen agora podemos levar alguns dos seus aspectos formais em consideração. Carmen não poderia fazer frente a Tristão, porque estruturalmente eram tão diferentes e irregulares que nem poderiam ser comparadas. Sendo assim, só nos resta considerar que não é tanto a forma que interessava a Nietzsche quando se apropriara da obra de Bizet. A afirmação da música não parecia dizer respeito apenas aos mais avançados processos composicionais, antes parecia ainda necessitada de uma crítica que fizesse jus à sua posição destacada à frente das demais formas artísticas .

O que o pensamento estético de Nietzsche antecipa é a função desagregadora da forma romântico-tardia que parece possuir a obra de Bizet. O uso "irônico" poderia ser visto então não como um recurso de oposição, uma confrontação entre formas musicais, mas como uma avançada compreensão acerca das mudanças estruturais pelas quais passava a música. Ignorando segmentações estanques, Nietzsche se reporta aos mais diversos universos sonoros, sem limites entre o que hoje opomos nos limites do erudito/popular. Sua distinção crítica de Bizet parece antecipar justamente a força reificadora do romantismo tardio, que 
contaminaria todos os processos composicionais, dos mais simplórios aos mais avançados - algo que Adorno atestou e diagnosticou como nenhum outro.

Sendo assim, o propósito deste artigo é recolocar alguns pontos clássicos da recepção de $\mathrm{O}$ caso Wagner, mas igualmente compreender como o tratamento dedicado ao tema da palavra musicada, que dava o tom da análise de Nietzsche naquele momento, pode ser recuperado como um aparato crítico que se encontra nos primórdios da crítica cultural tal como ela se desenvolveria no século 20. Para isso, como vimos, a recepção da obra de Nietzsche precisa ser analisada a partir do conjunto dos estudos monográficos restritos à academia, mas em aliança com uma face da recepção que quase nunca dialoga com os pesquisadores profissionais - o que tentamos demonstrar através da leitura de um crítico recente e muito destacado como Alex Ross.

Questões de todas essas ordens precisam ser analisadas a partir de um acurado estudo das fontes, destacando as leituras que Nietzsche realizou quando da redação d'O caso Wagner, que demonstrarão justamente com quem ele dialogava e se ele tinha interlocutores diante do que parecia impossível: demonstrar a força de uma crítica que se colocava diante do maior fenômeno musical popular com uma desconfiança inarredável e que ousava afirmar que aquilo não era o futuro, mas o esgotamento da música. Se Nietzsche acertou, o fez enviezadamente: as formas musicais de fato se transformaram, se "mediterranizaram", como ele previu, mas as consequências de sua vontade talvez não tenham seguido a direção apontada no seu último livro.

As formas clássicas se deterioraram, quase impedindo que algo fosse feito para além do que o drama musical wagneriano já fizera; a música popular comercial se tornaria 
hegemônica, tomando de assalto a maioria absoluta das relações comerciais e industriais. A música do futuro tornou-se algo impalpável, inclassificável, contrariando de muitas formas o intuito ambicionado por Nietzsche. Até que ponto podemos chamar a estética musical de Nietzsche de uma crítica antecipada da deterioração das formas? Nietzsche negara ou confirmara o futuro? Uma indagação de Manlio Sgalambro, citado num artigo importante de Gloria Sica, pode ser a grande pergunta desta pesquisa: teria sido Nietzsche, de fato, além de pai da música dionisíaca, o pai (ou parente próximo) da música ligeira? (SICA 2012).

Abstract: Taking as a fundamental axis The case Wagner (1888), this article will develop from the relationship between word and music on musical aesthetics late Nietzsche. The use of the Opera Carmen by George Bizet, as possibility of antithesis to the Total work of art program, the composer Richard Wagner, allows one to reflect on the aesthetics-Nietzschean musical of a privileged point of view. Why Nietzsche would have served as a work which he himself considered minor when compared to the Wagnerian musical drama? The answer to that question requires that you understand the deep value is not always clear from the word in musical compositions taken over by $\mathrm{Ni}$ etzsche at various times of his work. After all, his musical aesthetics favored the word significant or considered mere apparatus of absolute music?

Keywords: Friedrich Nietzsche; word; music.

\section{REFERÊNCIAS}

BARROS, Fernando Ribeiro de Moraes. "Música epistolar: Nietzsche e Carl Fuchs", São Paulo, Discurso Editorial, Cadernos Nietzsche, no 30, 2012, pp. 139-40.

D'IORIO, Paulo. "Nietzsche entre Tristão e Carmen" (tradução de Henry Burnett e Ernani Chaves). Estudos Nietzsche, Curitiba, v. 3, n. 2, p. 207-226, jul./dez. 2012.

GOETZ, Benoît. "Nietzsche aimait-il vraiment Bizet?", Le Portique [En ligne], 8/2001, in http://leportique.renues.org/index209.html. 
Acesso em 23/04/2015.

NIETZSCHE, Friedrich. Frühe Schriften (vol. 1: Jugendschriften 1861-1864), Herausgegeben von Hans Joaquim Mette, München, DTV, 1994.

NIETZSCHE, Friedrich. O Nascimento da tragédia (trad. Paulo César de Souza). São Paulo: Companhia das Letras, 1993.

NIETZSCHE, Friedrich. O caso Wagner/Nietzsche contra Wagner (trad. Paulo César de Souza). São Paulo: Companhia das Letras, 1999.

NIETZSCHE, Friedrich. "Fragmento 12[1]" (trad. Oswaldo Giacoia). In Revista Discurso no ${ }^{\text {36 }}$. São Paulo: Discurso Editorial, 2009.

ROSS, Alex. O Resto é Ruído: Ouvindo o Século XX, São Paulo, Companhia das Letras, 2009.

SAFATLE, Vladimir. "Destituição subjetiva e dissolução do eu na obra de John Cage", in Tania Rivera e Vladimir Safatle (Orgs.), Sobre arte e psicanálise. São Paulo: Editora Escuta, 2006.

SICA, Gloria. "La Carmen di Nietzsche" (2002), in http://www.sfi.it/archiviosfi/cf/cf10/articoli/sica.htm. Acesso em 23/04/2015.

SNELL, Bruno. "Aristófanes e a estética", in A cultura grega e as origens do pensamento europeu, São Paulo, Perspectiva, 2009. 